\title{
VALIDATION OF PUNCTURE SIMULATIONS OF RAILROAD TANK CARS USING FULL-SCALE IMPACT TEST DATA
}

\author{
Michael Carolan \\ Benjamin Perlman \\ Volpe National Transportation Systems Center \\ U.S. Department of Transportation \\ Cambridge, Massachusetts, USA
}

\author{
Francisco González III \\ Federal Railroad Administration \\ U.S. Department of Transportation \\ Washington, DC, USA
}

\begin{abstract}
The U.S. Department of Transportation's Federal Railroad Administration (FRA) has sponsored a series of full-scale dynamic shell impact tests to railroad tank cars. Currently, there are no required finite element (FE) model validation criteria or procedures in the field of railroad tank car puncture testing and simulation. Within the shell impact testing program sponsored by FRA, comparisons made between test measurements and simulation results have included the overall force-time or forceindentation histories, the puncture/non-puncture outcomes, the rigid body motions of the tank car, the internal pressures within the lading, and the energy absorbed by the tank during the impact. While qualitative comparisons (e.g. the shapes of the indentation) and quantitative comparisons (e.g. peak impact forces) have been made between tests and simulations, there are currently no requirements or guidelines on which specific behaviors should be compared, or what measurable level of agreement would be acceptable demonstration of model validation.
\end{abstract}

It is desirable that a framework for model validation, including well-defined criteria for comparison, be developed or adopted if simulation is to be used without companion shell impact testing for future tank car development. One of the challenges to developing model validation criteria and procedures for tank car shell puncture is the number of complex behaviors encountered in this problem, and the variety of approaches that could be used in simulating these behaviors. The FE models used to simulate tank car shell impacts include several complex behaviors, each of which can introduce uncertainty into the overall response of the model. These behaviors include dynamic impacts, non-linear steel material behavior, including ductile tearing, two-phase (water and air) fluid-structure interaction, and contact between rigid and deformable bodies.

Several candidate qualitative and quantitative comparisons of test measurements and simulations results are discussed in this paper. They are applied to two recently-completed shell impact tests of railroad tank cars sponsored by FRA. For each test, companion FE simulation was performed by the Volpe National Transportation Systems Center. The process of FE model development, including material characterization, is discussed in detail for each FE model. For each test, the test objectives, procedures, and key instrumentation are summarized. For each set of test and simulations, several corresponding results are compared between the test measurements and the simulation results. Additionally, this paper includes discussion of approaches to model validation employed in other industries or areas of transportation where similar modeling aspects have been encountered.

\section{INTRODUCTION}

In recent years, significant research has been conducted to analyze and improve the impact behavior and puncture resistance of railroad tank cars. Ultimately, the results of this research can be used by regulatory agencies in the United States and Canada (FRA and Transport Canada (TC), respectively) to establish performance-based testing requirements and to develop methods to evaluate the crashworthiness and structural integrity of different tank car designs when subjected to a standardized shell (i.e., the side of the tank) impact scenario. A performancebased requirement for tank car head (i.e., the end of the tank) impact protection has already been defined within the current U.S. regulations [1].

This material is declared a work of the U.S. Government and is not subject to copyright protection in the United States. Approved for public release; distribution is unlimited. 
The FRA has an ongoing research program to provide the technical basis for enhanced and alternative performance standards for tank cars. As a part of this program, new and innovative designs that are developed by the industry and other countries are also reviewed. In support of this research program, full-scale shell impact tests are necessary to provide the technical information to validate modeling efforts and to inform technology transfer and industry interaction activities. These tests evaluate the crashworthiness performance of tank cars used in the transportation of various categories of hazardous materials. The Volpe National Transportation Systems Center (Volpe Center) supports the FRA in this research effort, and has performed pre- and post-test finite element (FE) analyses alongside several of the full-scale shell impact tests. As shell impact testing of tank cars is destructive, expensive, and challenging to perform, this type of problem is an attractive candidate for FE modeling.

Since 2007, the FRA has sponsored a series of shell impact tests of tank cars of various designs. One of the key outcomes of each test is whether, under the defined impact conditions, the tank car was punctured or resisted the impact without puncturing. A table summarizing the shell impact tests is shown in Table 1. These shell impact tests have involved testing of tank cars constructed to various specifications, and included a mix of cars designed to carry pressurized gases or to carry flammable liquids. Some of these tests were performed as a part of a government-industry collaborative program referred to as the Next Generation Railroad Tank Car Project (denoted with an *).

Table 1. Summary of Tank Car Shell Impact Tests

\begin{tabular}{|c|c|c|c|c|c|}
\hline & $\underline{\text { Test Date }}$ & $\begin{array}{c}\text { Tank Car } \\
\text { Specification }\end{array}$ & $\frac{\text { Impact }}{\underline{\text { Speed }}}$ & $\frac{\text { Impactor }}{\underline{\text { Size }}}$ & $\underline{\text { Outcome }}$ \\
\hline $\begin{array}{c}\text { Test } \\
\text { 0* }\end{array}$ & $4 / 11 / 2007$ & DOT-105 & 10.0 & $\begin{array}{c}\text { 17in } x \\
\text { 23in }\end{array}$ & $\begin{array}{c}\text { No } \\
\text { Puncture }\end{array}$ \\
\hline $\begin{array}{c}\text { Test } \\
1 *\end{array}$ & 4/26/2007 & DOT-105 & 14.0 & $\begin{array}{c}\text { 17in } x \\
\text { 23in }\end{array}$ & $\begin{array}{c}\text { No } \\
\text { Puncture }\end{array}$ \\
\hline $\begin{array}{l}\text { Test } \\
2 *\end{array}$ & 7/11/2007 & DOT-105 & 15.1 & 6in $x$ 6in & Puncture \\
\hline $\begin{array}{c}\text { Test } \\
3 \\
\end{array}$ & 5/18/2011 & $\begin{array}{c}\text { DOT-105 } \\
\text { w/panel }\end{array}$ & 17.8 & $\begin{array}{c}\text { 12in } x \\
\text { 12in }\end{array}$ & $\begin{array}{c}\text { No } \\
\text { Puncture }\end{array}$ \\
\hline $\begin{array}{c}\text { Test } \\
4\end{array}$ & 5/18/2013 & DOT-111 & 14.0 & $\begin{array}{c}\text { 12in } \mathrm{x} \\
12 \mathrm{in}\end{array}$ & Puncture \\
\hline $\begin{array}{c}\text { Test } \\
5 \\
\end{array}$ & $2 / 26 / 2014$ & DOT-112 & 14.7 & $\begin{array}{c}\text { 12in } x \\
12 \text { in }\end{array}$ & $\begin{array}{c}\text { No } \\
\text { Puncture }\end{array}$ \\
\hline $\begin{array}{c}\text { Test } \\
6 \\
\end{array}$ & 4/27/2016 & DOT-105 & 15.2 & $\begin{array}{c}\text { 12in } x \\
\text { 12in }\end{array}$ & Puncture \\
\hline $\begin{array}{c}\text { Test } \\
7\end{array}$ & 9/28/2016 & DOT-117 & 13.9 & $\begin{array}{c}12 \text { in } x \\
12 \text { in }\end{array}$ & $\begin{array}{c}\text { No } \\
\text { puncture }\end{array}$ \\
\hline
\end{tabular}

From this table, it is apparent that only a small number of tank car shell impact tests have been performed over the past decade. Additionally, no two tests have had exactly the same impact conditions. While each test produced useful data for both understanding the shell impact response of a tank car under those particular conditions and for comparing with FE models, the test data do not span every conceivable shell impact scenario. FE modeling is used in conjunction with the tests to plan for the impact conditions, estimate the tank's response under those conditions, evaluate alternative impact conditions, and extrapolate from the test conditions to other conditions of interest.

A primary purpose for pre-test modeling is to estimate the target impact speed for an upcoming test, and how that speed may relate to a threshold puncture speed. One of the goals in performing a test is to estimate the threshold puncture speed of the tank car being tested under the prescribed impact conditions. Puncture speed is an attractive metric to use in comparing the relative performance of different tank car designs under similar impact conditions as the goal of the research program is to improve the performance of tank cars involved in incidents, including minimizing the loss of product. The threshold puncture speed can be thought of as the maximum speed at which the tank car can be impacted under the prescribed conditions without resulting in a tear to its shell that would allow its lading to escape.

A test speed that is too high will result in excessive destruction of the tank car, while a test speed that is too low may not provide enough data to be useful. The threshold puncture speed of the tank car is the speed at which, under the test conditions, the initial kinetic energy of the ram is exactly equal to the energy necessary to puncture the tank shell. At this speed, an incrementally slower test would be a non-puncture test, and an incrementally faster test would exceed the capacity of the tank car to resist puncturing. Due to manufacturing variability, variation in material properties, accuracy of measurement, and limitations on the test setup, the threshold puncture speed can be thought of as a range of speeds rather than a single numerical value. This concept is shown schematically in Figure 1.

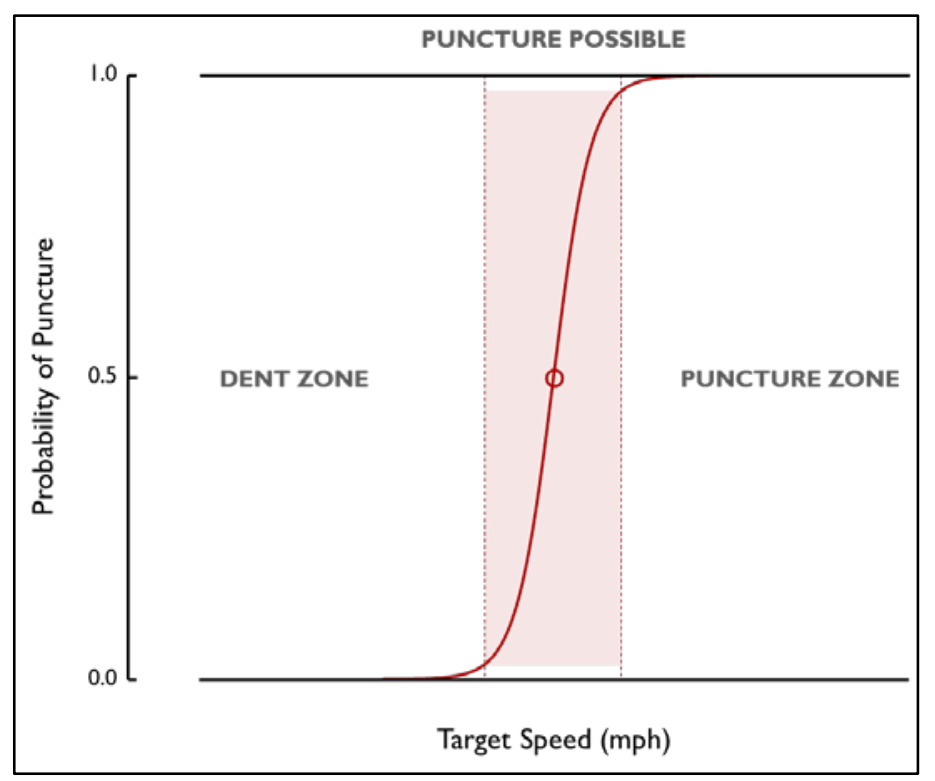

Figure 1. Schematic Illustration of Probability of Puncture

Companion FE modeling has been performed alongside each test. Ideally, the pre-test FE model is capable of predicting all of the responses that are measured or observed during the test. In practice, some difference between the FE results and the test measurements is expected. Additionally, based on the actual

This material is declared a work of the U.S. Government and is not subject to copyright protection in the United States. Approved for public release; distribution is unlimited. 
impact conditions (e.g. measured impact speed, post-test material characterization), it is usually necessary to make some adjustment to the pre-test model after the test to be able to simulate the actual test conditions, creating a post-test model. Depending on the nature of the changes made to the model, these changes may be considered model calibration, where the intent is to adjust the physical modeling parameters in the model to better match the test data, or may simply be adjustments to the pre-test model to better match the actual test conditions [2].

Expecting there will be some difference between the test measurements and corresponding results from an FE model, it is valuable to develop targets for comparisons to be made between the test measurements and FE results to be used to validate that the model is producing physically-realistic results for the system being modeled [2]. This is especially important if an FE model is intended to be used to simulate conditions beyond what was tested, as there will not be corresponding test data to serve as a check on the reasonableness of the model's results.

While FE model results have been compared to test measurements for each of the tests summarized in Table 1, there are currently no requirements or formal guidelines on which specific behaviors should be compared, or what measurable level of agreement would be acceptable demonstration of model validation. This paper focuses its discussion on the two most recent shell impact tests and companion FE analyses: a DOT-105 tank car (April 27, 2016) [3] and a DOT-117 tank car (September 28, 2016) [4]. Further discussion of other tests and analyses can be found in the respective test reports (references [5][6][7]).

\section{SHELL IMPACT SCENARIO}

For the tank car shell impact test, a standardized, repeatable, controllable, and safe impact scenario was chosen. The tank car undergoing testing is removed from its trucks (bogies) and placed on two skids intended to limit the amount of roll that can occur after impact. The tank car is then placed perpendicular to a set of railroad tracks, with the area of the shell to be impacted centered between the rails. The tank car is placed against a stiff wall, limiting its ability to move away from the impacting car. A heavy ram car, equipped with the desired impact head, is pulled back up a track with a descending grade that ends at the rigid wall. Based on the desired test impact speed, the ram car is released from an appropriate distance up this track. The ram car accelerates under gravity, ideally reaching the desired impact speed at the instant of contact between the end of the impact head and the shell of the tank car being tested. The test setup is shown in Figure 2 for the test of the DOT-117 tank car.

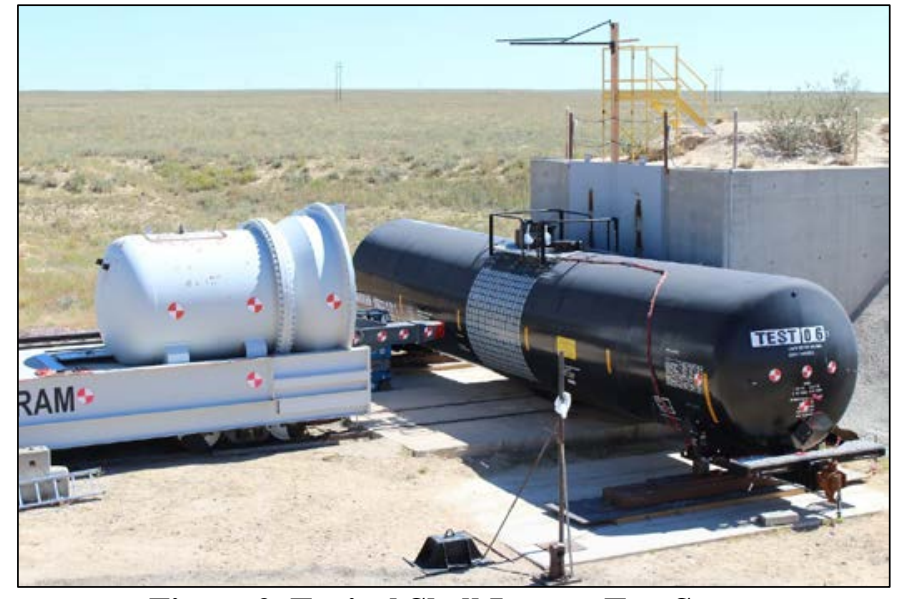

Figure 2. Typical Shell Impact Test Setup

This test setup creates a severe impact condition for the tank car's shell, as the kinetic energy of the initially-moving ram car must be dissipated through deformation of the struck tank car, with relatively little ability for the tank car to move out of the path of the impactor. As shown in Table 1, a variety of impact heads have been used in the tests conducted to-date. While the ram car's weight fluctuates depending on the particular impact head fitted to it, this car weighed approximately 297,000 pounds in the two most recent tests. Based on the weight of the ram car and the measured impact speed, the initial kinetic energy of the impact can be calculated.

Table 1 provides a brief summary of each full-scale shell impact test, but does not explain all of the details that differed from testto-test. Generally, each specification tank car is designed to carry a particular commodity or class of commodities. The design of each specification tank car has been optimized based on the requirements and characteristics of those commodities. Additionally, tank cars are not completely filled with lading, but have an intentional outage left at the top to allow for the commodity to expand en route. Different specification tank cars carrying different commodities will have different outage volumes. For example, the DOT-105 tank car discussed in this paper was designed to carry pressurized gases, while the DOT117 tank car was designed to carry flammable liquids. The test setup used in each test reflected the operational conditions of the tank car, with the tested DOT-105 tank car having an internal pressure of 100 psig and approximately 10 percent outage, and the DOT-117 initially at atmospheric pressure with approximately 5 percent outage. As will be discussed later, the initial internal pressure affects the overall characteristic of the shell impact response.

\section{INSTRUMENTATION AND TEST RESULTS}

The instrumentation setup can vary slightly from test-to-test, depending on the details of the test, the tank car being tested, and the desired measurements. In general, each test includes instrumentation on both the initially-moving ram car and the initially-standing tank car. Tape switches are installed on the surface of the impact head and in the contact zone on the tank itself to allow the data acquisition systems on the ram car and the

This material is declared a work of the U.S. Government and is not subject to copyright protection in the United States. Approved for public release; distribution is unlimited. 
struck tank car to be synchronized to the time of impact. The instrumentation used in the DOT-105 and DOT-117 tests are summarized in Table 2.

Table 2. Instrumentation Summary

\begin{tabular}{|l|c|c|}
\hline \multirow{2}{*}{$\begin{array}{c}\text { Type of } \\
\text { Instrumentation }\end{array}$} & \multicolumn{2}{c|}{ Channel Count } \\
\cline { 2 - 3 } & DOT-105 Test & DOT-117 Test \\
\hline Accelerometers & 11 & 11 \\
\hline Speed Sensors & 2 & 2 \\
\hline $\begin{array}{l}\text { Pressure } \\
\text { Transducers }\end{array}$ & 11 & 12 \\
\hline $\begin{array}{l}\text { String } \\
\text { Potentiometers }\end{array}$ & 10 & 10 \\
\hline Total Data Channels & 34 & 35 \\
\hline
\end{tabular}

In addition to the measurements from the test instrumentation, one of the most readily apparent results of the test is whether the tank car punctured or resisted the impact without puncturing. This behavior, as well as the measured test data, are all candidates for inclusion in a program of model validation.

\section{Accelerometer Data}

Accelerometers and speed sensors are installed on the ram car to determine the impact speed and to measure the ram's deceleration. Accelerometers are also used to determine if the ram car experienced significant vertical or lateral motions. By numerically integrating the acceleration-time history and using the impact speed as the initial condition, the velocity-time history of the impact can be calculated. By subsequently integrating the velocity-time history from the instant of impact, the displacement-time history of the impactor can be calculated. Finally, using the mass of the ram car and its longitudinal decelerations, the force-time history of the impact can be calculated.

Each of the five longitudinal accelerometer channels on board the ram car is processed using a CFC60 filter consistent with the methods described in SAE J211 [8]. Close agreement among the five longitudinal accelerometer channels on the ram car indicates that the ram car is generally behaving as a rigid body. Thus, the filtered acceleration channels are averaged to provide a single acceleration-time history for the ram car.

\section{String Potentiometer Data}

String potentiometers (string pots) are used to measure displacements between points of interest inside and outside of the struck tank car. Typically, a longitudinally-oriented string pot is installed between each support skid and ground, and at the center of the head at each end of the tank car and ground. These string pots will measure the overall displacements of the support locations and the ends of the car, away from the impact zone. Closer to the point of impact, five longitudinal string pots are installed between the 9 o'clock and 3 o'clock positions on the interior of the tank. These five string pots are spaced every 2-feet along the length of the shell, and can be used to capture the overall gradient of the indentation of the tank shell. One string pot is installed vertically inside the tank (between 12 o'clock and 6 o'clock) and is used to measure the ovalization of the tank as it deforms. If the internal pressure increase during the test is expected to be significant, additional string pots can be used to measure travel of the pressure relief valve (PRV). No averaging is performed on string pot data, as each channel measures the displacements between two discrete points in space.

\section{Pressure Transducer Data}

The struck tank car typically features an array of pressure transducers inside the tank. These pressure transducers are placed at multiple cross-sections of the shell along the length of the tank, typically at the $3,6,9$, and 12 o'clock positions. This arrangement means that some of the transducers are located in the lading (water, in the most recent two tests), while others are located in the outage space.

Each pressure transducer data channel is typically processed using a CFC60 filter. While the pressure transducers represent measurements of pressure-time history at discrete points in either the lading or the outage, averaging may be performed to examine the average outage pressure-time history or average lading pressure-time history.

\section{FE MODEL DEVELOPMENT}

The Abaqus/Explicit commercial FE program was used to simulate both the DOT-105 and DOT-117 shell impact tests [9]. This impact problem presents several challenges to simulation, each of which will affect the ultimate performace of the FE model and its suitability to simulate further impact conditions. The shell impact problem involves a dynamic impact with contact that evolves over time. The tank car shell will undergo elastic and plastic deformations, necessitating a material response for the steel shell that can adequately capture both behaviors. The model must also be capable of determining if puncture is likely to occur and if so, implementing a physicallyrealistic numerical representation of material failure. The tested cars featured fluid-structure interactions between the tank shell and two different fluid species, lading (water) and outage (air). Depending on the test conditions, it may also be necessary to represent the tank car's PRV within the model, should tank deformation result in an adequate rise in outage pressure to begin to vent.

For each shell impact test, the pre-test FE model includes a combination of deformable and rigid parts. For the DOT-105 and DOT-117 tank car impact tests, half-symmetric FE models were used to reduce computation time. Based on previous test experience and the use of a half-symmetric model, the impactor is typically modeled as a rigid body having a point mass equal to half the total mass of the ram car with impact head. The backing wall and skids are also modeled as rigid bodies. The tank car and its two-phase contents are represented as deformable bodies. The overall setup is shown in Figure 3 for the DOT-105 shell impact FE model. This model used shell elements for most of the tank and jacket, with a patch of solid elements in the tank's impact zone. Shell-to-solid coupling constraints were defined at the interfaces between the two different types of elements.

This material is declared a work of the U.S. Government and is not subject to copyright protection in the United States. Approved for public release; distribution is unlimited. 


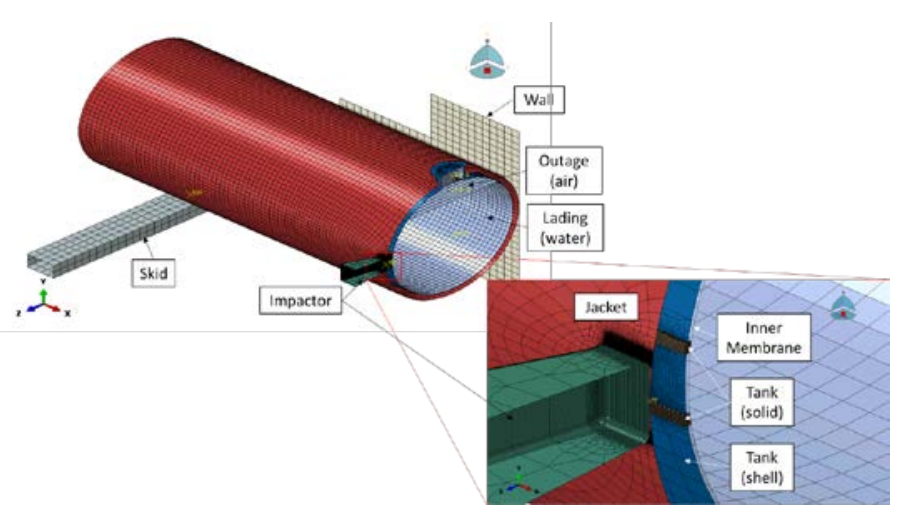

Figure 3. Annotated FE Model for DOT-105 Simulations

Material behaviors must be defined within each pre-test model for the tank, external jacket, water (lading), and air (outage). The focus of discussion in this technical paper will be the TC128 steel making up the tank car's shell. Further details on the approaches used to model the remaining materials in the tank cars can be found in the respective test report (references [3] and [4]).

For each FE model used to simulate a shell impact test, the model had to be capable of capturing puncture if the impact conditions would cause puncture in an actual test. Thus, the material behaviors defined within each model included the elastic-plastic response of the steel, and additional parameters to estimate the onset of material failure (puncture). The technique selected for modeling puncture employed a triaxiality-based ductile failure model within the Abaqus software that is based on work done by Bao and Wierzbicki [10]. Further work by Lee and Wierzbicki [11] led to the development of a "quick-calibration” method of generating the parameters needed for ductile failure of a material within the FE model using common tensile test coupons. After each impact test, material coupons were excised from undeformed areas of the tested tank car. These coupons were subjected to tensile tests according to ASTM E-8 [12]. From the results of the tensile tests, the material parameters necessary to model the elastic-plastic response and generate the triaxialitybased ductile failure initiation envelope were developed by simulating the tensile tests within Abaqus. In this approach, the mesh used to model the tensile coupons was carefully generated such that elements of a similar size were used in both the tensile coupon model and the tank car impact model to reduce the effects of mesh size on material parameters.

Figure 4 contains a plot showing the engineering stress-strain responses from tensile tests on six coupons taken from the DOT105 tank car and three coupons taken from the DOT-117 tank car. This figure also shows the results of FE analyses of a coupon test of each tank car's material. From this figure, it is apparent that while both tank cars were made from TC128 steel, the actual tensile response can exhibit a significant variation in strength and ductility across different cars made from the same specification of material. While minor variation was observed in the TC128 behavior from the coupons excised from the same car, this variation was not as significant as the variation across different cars.

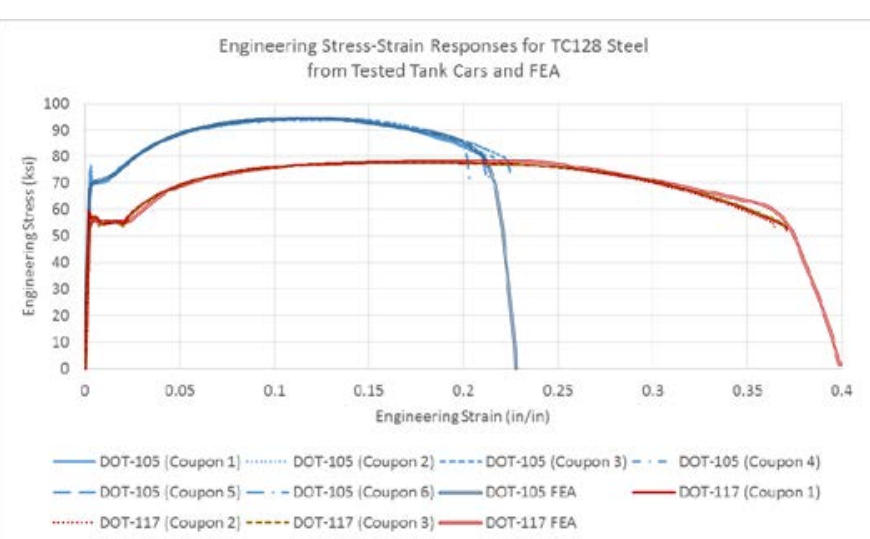

Figure 4. Engineering Stress-Strain Responses for TC128 Steel from Tested Tank Cars and FEA

These results also provide an indication that as the strength of the TC128 material increases, its ductility decreases. Because both the material's strength and ductility can have an effect on the puncture resistance of the tank car's shell, understanding the material properties of the actual material of construction may be an important element to consider in assessing the validity of a particular tank car model. The variation in material behaviors across different cars made of material meeting the same specification poses a challenge to using a particular material response to extrapolate to a tank car manufactured at a different time, by a different manufacturer, or using steel from a different origin, as the actual material properties for the tank car of interest can only be known by testing that particular material.

\section{COMPARISON OF FE RESULTS AND TEST RESULTS}

Typically, the test measurements from each data channel, or an average of several channels measuring the same behavior (e.g., outage pressure) are compared with corresponding calculations from the FE model. Several exemplar comparisions are presented here as illustrations of the data comparisons typically made for a tank car shell impact. It should be noted that these comparisons do not represent all of the comparisions made in the respective test reports (references [3] and [4]). Further, this section intentionally excludes discussion or commentary on the adequacy of the comparisons, the quality of the agreement or disagreement, and the quantitative level of agreement, as one objective of this paper is to examine existing criteria and procedures for model validation that may be suitable for application to the tank car shell impact problem.

For both the DOT-105 and the DOT-117 tank car tests, an overall comparison between the FE calculations and the test measurements is the force-time history of the impact. For both the test and the model, the force represents the average deceleration of the ram car multiplied by its mass. The accelerations measured during the impact are initially negative, indicating deceleration of the initially-moving ram. These negative values are converted to positive values when calculating the impact force imparted to the impacted tank. All of the results shown in this paper were obtained using post-test FE models using the actual TC128 material properties for the respective tank car.

This material is declared a work of the U.S. Government and is not subject to copyright protection in the United States. Approved for public release; distribution is unlimited. 
Figure 5 contains a plot of the force-time histories from the DOT105 test and post-test FE model. Figure 6 contains a plot of the force-time histories from the DOT-117 test and post-test FE model. From these two figures, it is apparent that the DOT-105 and DOT-117 tank cars exhibited different structural responses under substantially-similar impact conditions. Recall that the DOT-105 tank car was initially pressurized to $100 \mathrm{psig}$, while the DOT-117 was initially at atmospheric pressure. The DOT-105 tank car experienced a fairly-constant increase in force, while the DOT-117 exhibits a plateau in force between approximately 0.05 and 0.1 seconds. The DOT-105 experiences a higher peak force than the DOT-117, while the DOT-117 impact event takes place over a longer duration than the DOT-105. Finally, the DOT-105 tank car experienced a puncture during the test, whereas the DOT-117 did not. For each tank car, the FE analysis produced the same puncture or non-puncture response as occurred in the test. The DOT-105 model was terminated after the onset of puncture. The DOT-117 model terminated shortly after the impactor began to rebound from the tank car.

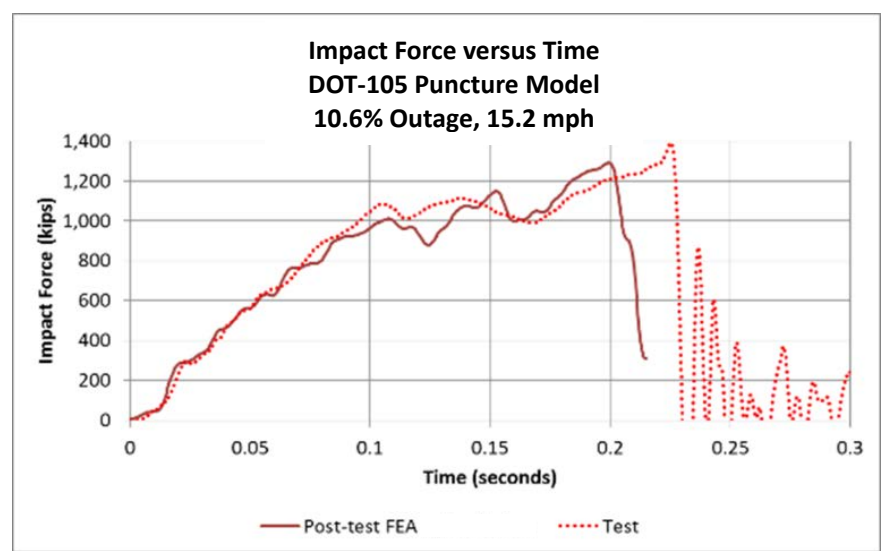

Figure 5. DOT-105 Force-Time History (CFC60)

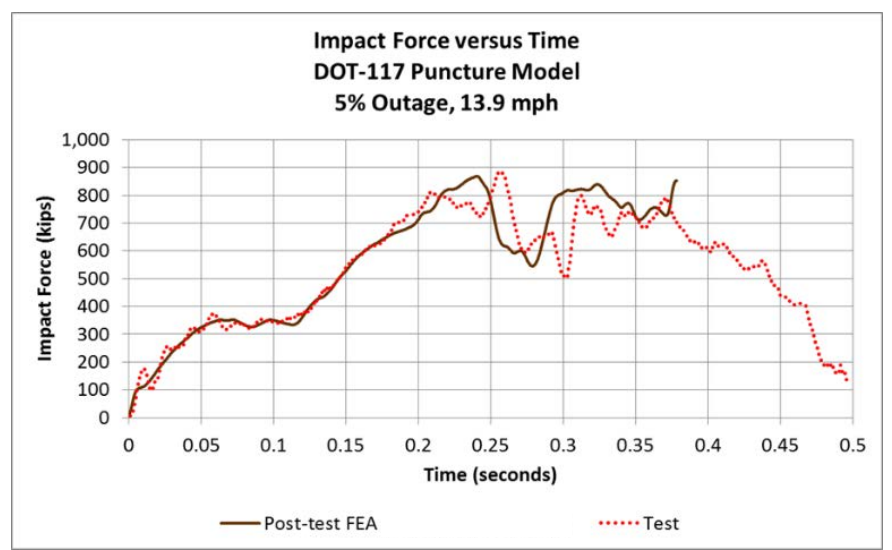

Figure 6. DOT-117 Force-Time History (CFC60)

Another overall comparison of test and FE results that is often made is the force-indentation response of the impact. "Indentation" is the distance traveled by the impactor starting from first contact with the tank car. Several behaviors of the impact system can be more readily examined when force is plotted against impactor travel rather than time. Regardless of the puncture/non-puncture outcome, the force acting on the ram car eventually drops to zero as time increases, as the impactor always comes to a stop. However, when the abscissa of the force plot is impactor travel, puncture and non-puncture responses exhibit two different behaviors. If the impact causes puncture of the tank, the force will drop rapidly as the impactor continues to penetrate the tank, as the tank has lost its ability to substantially resist further travel of the impactor. However, in a non-puncture impact, the impactor will be brought to a stop by the tank, and begin to rebound. The non-puncture response is apparent from the indentation reaching a maximum value, then gradually decreasing as the impactor rebounds.

Figure 7 shows the force-indentation responses from the DOT105 test and FE analyses. This test resulted in puncture of the tank in both the test and in the model. The force drops suddenly after an indentation of approximately 38 inches.

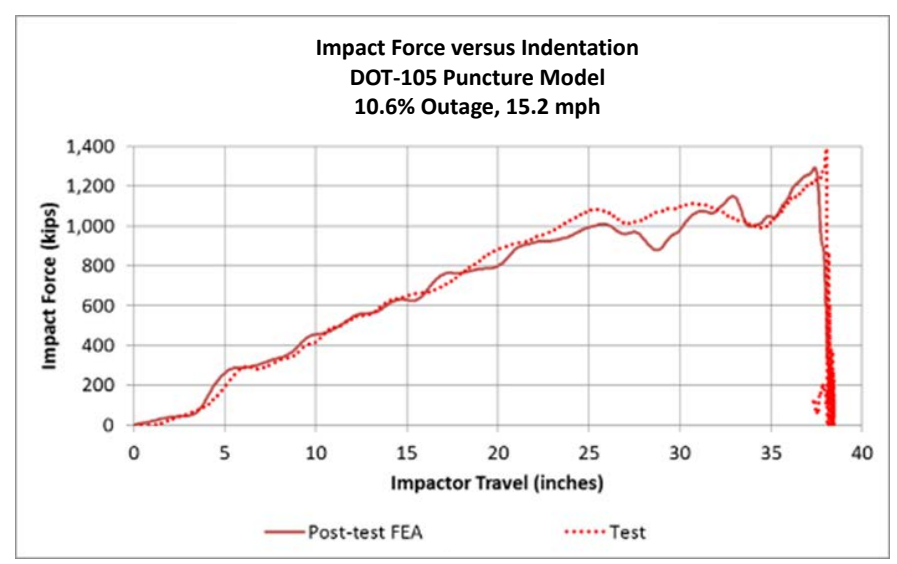

Figure 7. DOT-105 Force-Indentation History (CFC60)

Figure 8 shows the force-indentation responses from the DOT117 test and FE model. This test did not result in puncture of the tank in the test. The FE model exhibited a small number of failed elements in the tank shell, but did not fully puncture and causes the impactor to rebound.

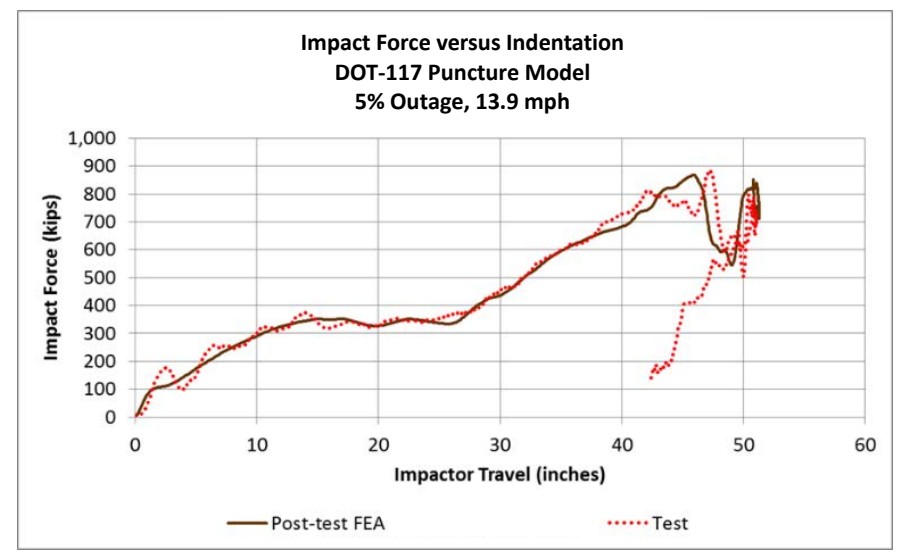

Figure 8. DOT-117 Force-Indentation History (CFC60)

As a means of assessing the fluid response, the outage pressure is typically compared between the test measurements and the FE results. The air modeling technique used in both the DOT-105 and DOT-117 FE analyses results in the calculation of a single

This material is declared a work of the U.S. Government and is not subject to copyright protection in the United States. Approved for public release; distribution is unlimited. 
average pressure value applied over the entire outage volume. Figure 9 contains a plot of the average outage pressure from the DOT-105 FE model and the pressure in the outage at the manway from the DOT-105 test.

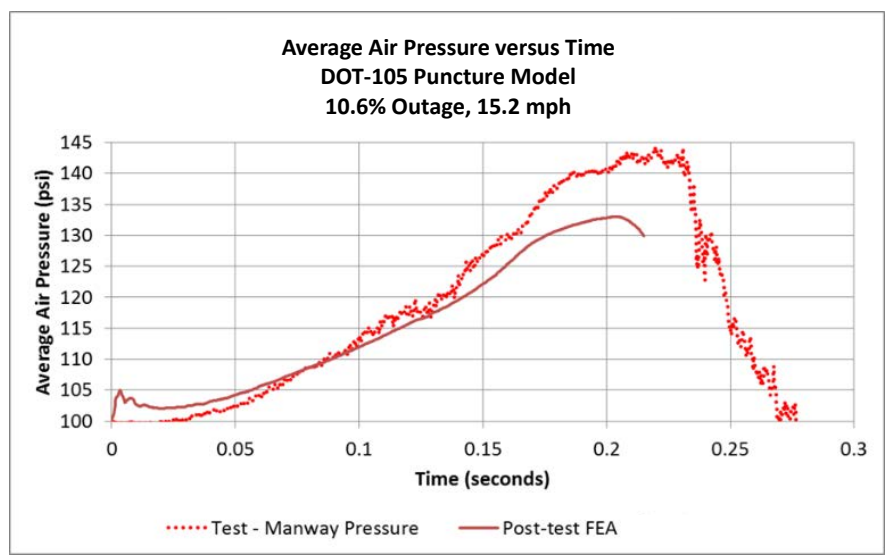

Figure 9. Average (FEA) and Manway (Test) Air PressureTime Histories from DOT-105 (CFC60)

Figure 10 contains a plot of the average outage pressure from the DOT-117 FE model alongside the average outage pressure from the DOT-117 test. The FE model featured a simulated PRV that was set to allow air to escape if the average air pressure reached 75 psi.

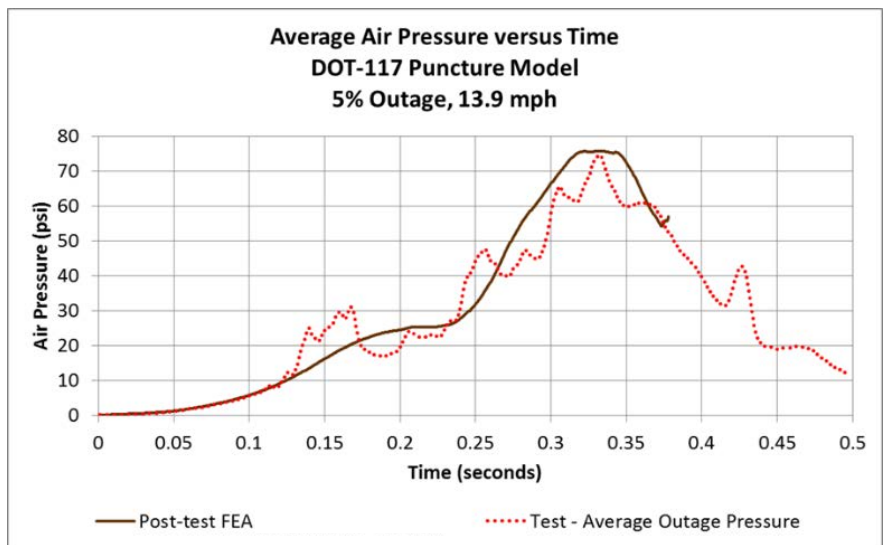

Figure 10. Average Air Pressure-Time Histories from FEA and Test for DOT-117 (CFC60)

Figure 11 contains a plot of the displacement-time histories from the A- and B-end skids beneath the DOT-105 tank car, and Figure 12 contains a corresponding plot for the DOT-117 tank car. Each of these figures also includes the displacement-time history from the skid in the corresponding FE model. There is only one series of FE data on each plot since the FE models were halfsymmetric. For each tank car, there is an apparent delay between impact and when the skids begin to move. In each test, the skid string pot reaches a minimum value (representing the greatest distance traveled in the direction of impact) before the skid reverses direction and begins to move away from the wall.

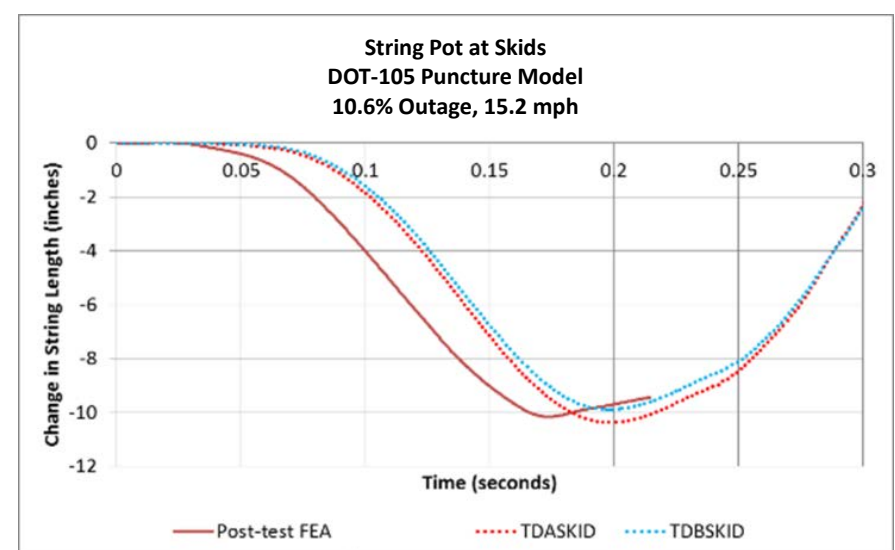

Figure 11. Skid Displacement-Time Histories for DOT-105 Test and FEA

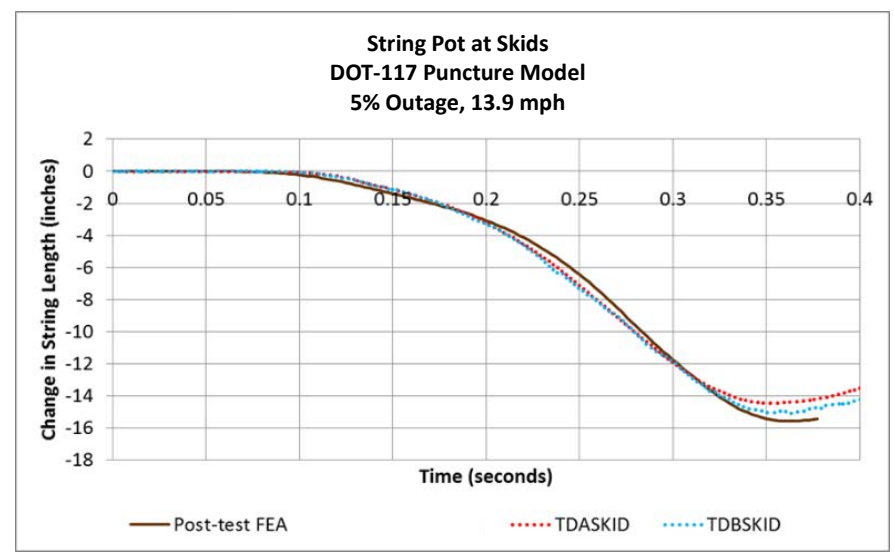

Figure 12. Skid Displacement-Time Histories for DOT-117 Test and FEA

\section{EXAMPLES OF EXISTING MODEL VALIDATION CRITERIA \& PROCEDURES}

The above test and FE results contain examples of the types of comparisons typically made for tank car shell impact tests, but do not contain discussion of whether these are the appropriate comparisons to make, or of the quality of the level of agreement between the values compared. Various standards, regulations, or guidance documents (collectively, "design documents") used in different modes of transportation that contain model validation criteria and procedures were reviewed to understand the qualitative and quantitative comparisons that are typically used in other areas of engineering that may be applicable to the tank car shell impact problem.

\section{Rail Equipment}

While dynamic impact testing and analyses have become more commonly employed in evaluating rail vehicles, the majority of the design documents addressing model validation are oriented toward evaluating the design of passenger rail vehicles, not tank cars. However, several of these design documents do include criteria and procedures for performing dynamic impact analyses, which may be useful in addressing some of the challenges associated with developing model validation guidance for the tank car shell impact problem.

This material is declared a work of the U.S. Government and is not subject to copyright protection in the United States. Approved for public release; distribution is unlimited. 


\section{EN 15227}

In Europe, passenger rail vehicle designs may be evaluated using one or more dynamic impact scenarios described in standard EN 15227 [13]. This design document includes up to five dynamic impact scenarios, depending on the intended service environment of the passenger vehicle undergoing evaluation (e.g. operating only with like vehicles, sharing tracks with freight trains, etc.). Thus, FE modeling is expected to be used to demonstrate compliance, rather than full-scale impact testing of the applicable scenarios.

EN 15227 uses the concept of "validation" to refer to two different assessments. According to EN 15227, a passenger rail vehicle's design is “validated" by demonstrating that it meets the crashworthiness criteria for the applicable scenarios. EN 15227 also refers to "validating" a numerical model by comparing its results with those of tests. This technical paper is focused on EN 15227's discussion of validating a numerical model, not on demonstrating the crashworthiness of an entire passenger rail vehicle.

Because EN 15227 is intended to be applied to passenger rail vehicles with crash energy management (CEM) systems, its model validation approach is focused on validating models of the energy-absorbing components that will be engaged during dynamic impact simulations. EN 15227's criteria for model validation of energy-absorbing components includes demonstrating that the sequence of events is "the same" between the test and the model, the deformation patterns are "the same," the absorbed energies from the test and the model are within 10 percent of one another, and that the global force-crush curve in the model "exhibits the same general characteristics as measured in the test" [13]. For more complex CEM arrangements, in which several components may absorb energy in parallel, EN 15227 sets the criteria for validation as the overall displacement of the system being within 10 percent, and average force measured during crush being within 10 percent.

Finally, EN 15227 discusses the types of changes that can be made to a post-test model that would still be considered validated. It states that ideally, only "the mass and speed should be adjusted" in the simulation to obtain agreement with the test measurements. EN 15227 also recommends using material properties based on the actual material(s) of construction in the energy-absorbing device, rather than nominal properties.

\section{Engineering Task Force / Notice of Proposed Rulemaking}

In the U.S., the FRA promulgates regulations for the structural crashworthiness of passenger rail vehicles. If a passenger rail vehicle is subject to FRA's regulations but does not meet the requirements of the applicable regulations, the entity seeking to operate the vehicle or its manufacturer may request a waiver of the regulation from FRA. In 2011, FRA published a report entitled Technical Criteria and Procedures for Evaluating the Crashworthiness and Occupant Protection Performance of Alternatively Designed Passenger Rail Equipment for Use in Tier I Service that was developed by the Railroad Safety Advisory Committee's Engineering Task Force (ETF) [14]. This report contained guidance on submitting a request for a waiver for rail vehicles that were originally evaluated using a design document other than the conventional U.S. requirements, but which may be capable of demonstrating an equivalent level of safety to equipment that was designed to meet conventional U.S. requirements. This design document includes a static compression load case for the carbody structure, as well as a dynamic impact scenario between passenger trains.

Because FE simulation could be used to evaluate either or both the static compression load case and the dynamic collision scenario, this report also contains targets for model validation. For simulating the static carbody structure loads, the model is to first be validated with elastic compression test data. Strain results are to be within $+/-20$ percent, and displacement results are to be within $+/-10$ percent of the validation test measurements. This document does not contain explicit requirements for validating the dynamic model used to evaluate the collision scenario.

In 2016, FRA published a Notice of Proposed Rulemaking (NPRM) that sought to incorporate many of the criteria and procedures developed by the ETF into future regulations [15]. One difference between the NPRM and the ETF's Technical Criteria and Procedures report is that the NPRM specifically requires model validation to be performed for both the model used in the static simulation and the dynamic collision scenario. However, the NPRM does not list specific measurements that must be compared, nor target values for agreement between test and analysis for dynamic model validation.

\section{Other Modes of Transportation}

Roadside Safety Hardware

FE analysis is often used in the development of roadside safety hardware features (guardrails, end terminals, sign posts, etc.). Because these safety features are intended to function under impact conditions, dynamic impact analyses are often used to understand the performance of roadside safety hardware. This hardware is also frequently tested to demonstrate its performance before being placed into service. This testing involves different categories of highway vehicles (e.g. light cars, pickup trucks, etc.) striking the roadside safety hardware feature under prescribed impact conditions given in design documents [16].

Modeling these impact scenarios can be complex, as both the striking object (i.e. the highway vehicle) and the struck object (i.e. the roadside safety hardware undergoing evaluation) can experience large deformations during the impact. The striking vehicle can experience 3-dimensional motion, and complicated contact can occur as the involved bodies deform. A guidance document, NCHRP Web-Only Document 179: Procedures for Verification and Validation of Computer Simulations Used for Roadside Safety Applications (NCHRP W179) has been developed to provide a standardized approach to comparing the performance of a simulated impact event to an actual test [17].

This guidance document lays out an overall framework for evaluating a proposed modification to an existing design for roadside safety hardware that has already been crash-tested. The

This material is declared a work of the U.S. Government and is not subject to copyright protection in the United States. Approved for public release; distribution is unlimited. 
framework includes identifying a suitable baseline test, modeling the baseline test and comparing the results of the model to the test, modifying the model to represent the change being considered, and then finally using the model of the modified design to evaluate its performance against the applicable design document.

Alongside the criteria and procedures given in NCHRP W179, a companion software package (Roadside Safety Verification and Validation Program, or RSVVP) has been developed to facilitate the comparison between time histories of test measurements with computer simulation results of the same impact event [18]. This software includes several metrics for performing a quantitative comparison between a test measurement and corresponding simulation result.

\section{Automobile Crashworthiness}

The automotive industry makes extensive use of dynamic simulations for both structural crashworthiness and occupant protection of passenger vehicles. CORA (CORrelation and Analysis) is a software program that was developed by a group of automobile manufacturers to provide "an objective evaluation of time-history signals," using a "corridor rating and a crosscorrelation rating” [19]. This software was originally developed for use in the field of anthropomorphic test device (i.e., "test dummy") evaluation, meaning that it is intended to be used to evaluate dynamic impact responses.

ISO/TS 18571 is a standard for "validation metrics and rating procedures to be used to calculate the level of correlation between two non-ambiguous signals obtained from a physical test and a computational model, and is aimed at vehicle safety applications" [20]. This design document incorporates the CORA corridor model, but expands upon it to also include phase, magnitude, and slope analyses to determine an overall ISO rating in the form of a numerical score.

\section{Aircraft Seats}

The Federal Aviation Administration (FAA) Advisory Circular (AC) 20-146 Methodology for Dynamic Seat Certification by Analysis for Use in Part 23, 25, 27, and 29 Airplanes and Rotorcraft provides guidance and example procedures for validating computer models of aircraft seats [21]. This document lays out a methodology for using analysis to demonstrate that a modification to a previously-tested seat design that meets the applicable requirements will also meet the applicable requirements. The methodology described in AC 20-146 includes testing the original seat design, simulating this test, demonstrating that the simulation produces results within a certain level of agreement with the test, and only then using the simulation to represent the proposed modification to the original seat design.

\section{EXAMPLES OF BEHAVIORS CONSIDERED FOR COMPARISON BETWEEN TESTS AND ANALYSES}

While established procedures for comparing test and FE analysis results specific to the tank car shell impact problem do not currently exist, there are several behaviors that are desirable for comparison between testing and simulation as part of a program of model validation.

\section{Magnitudes of Compared Values}

One of the basic approaches to comparing model results with test measurements is to identify key measurements for comparision and determine the percent difference between the peak value measured in the test and the peak value calculated by the model. This approach is straightforward, and allows the entity making the comparison to assess the level of agreement by means of a simple percentage. This is the approach used by the ETF in its Technical Criteria and Procedures report [14], with different target thresholds for different types of measurements. However, those thresholds are for quasi-static modeling and testing.

Further refinement of a magnitude comparison could be obtained by setting a target number of channels that should be compared, and a second target on the number of those channels that must be within the allowable difference between test and analysis. As an illustration of this approach, the peak measurements from the FEA and test measurements from the DOT-105 and DOT-117 tank car shell impacts are shown in Table 3.

Table 3. Summary of Peak Measurements and FE Results

\begin{tabular}{|c|c|c|c|c|c|}
\hline & & \multicolumn{2}{|c|}{ DOT-105 } & \multicolumn{2}{|c|}{ DOT-117 } \\
\hline & & FEA & Test & FEA & Test \\
\hline $\begin{array}{l}\text { Longitudinal } \\
\text { Acceleration }\end{array}$ & G & -4.3 & -4.7 & -2.9 & -3.0 \\
\hline Impact Force & kips & $1,292.3$ & 1,390 & 868 & 883.8 \\
\hline $\begin{array}{l}\text { Displacement } \\
\text { at Peak Force }\end{array}$ & in. & 37.4 & 38.0 & 45.9 & 47.3 \\
\hline $\begin{array}{l}\text { Peak Energy } \\
\text { Absorbed }\end{array}$ & $\begin{array}{c}10^{6} \\
\text { ft-lbf }\end{array}$ & 2.2 & 2.3 & 1.91 & 1.91 \\
\hline \multirow{2}{*}{$\begin{array}{c}\text { 48-inch } \\
\text { Offset String } \\
\text { Pot. }\end{array}$} & in. & -17.4 & $\begin{array}{l}-15.8 \\
\end{array}$ & -36.8 & -38.1 \\
\hline & in. & -17.4 & -18.2 & -36.8 & -38.7 \\
\hline \multirow{2}{*}{$\begin{array}{c}\text { 24-inch } \\
\text { Offset String } \\
\text { Pot. }\end{array}$} & in. & -23.8 & -23.6 & -43.3 & -44.8 \\
\hline & in. & -23.8 & -24.5 & -43.3 & -45.1 \\
\hline $\begin{array}{c}\text { Center String } \\
\text { Pot. }\end{array}$ & in. & -31.0 & -30.6 & -49.1 & -47.3 \\
\hline $\begin{array}{c}\text { Vertical } \\
\text { String Pot. }\end{array}$ & in. & 11.5 & 17.2 & 18.3 & 19.5 \\
\hline \multirow{2}{*}{$\begin{array}{l}\text { Skid String } \\
\text { Pots. }\end{array}$} & in. & -10.2 & -10.4 & -15.6 & -14.4 \\
\hline & in. & -10.2 & -9.9 & -15.6 & -15.1 \\
\hline \multirow{2}{*}{$\begin{array}{l}\text { Head String } \\
\text { Pot. }\end{array}$} & in. & -9.8 & -10.3 & -15.7 & -15.3 \\
\hline & in. & -9.8 & -9.8 & -15.7 & -16.0 \\
\hline $\begin{array}{l}\text { Outage } \\
\text { Pressure }\end{array}$ & psi & 133.0 & 144.3 & 75.7 & 74.6 \\
\hline
\end{tabular}

While comparing the peak value for each measurement in a test with a corresponding value in the $\mathrm{FE}$ results enables an assessment of the percentage difference between the two values to be made quickly and compared with an agreed-upon threshold, this approach also has several drawbacks. For a

This material is declared a work of the U.S. Government and is not subject to copyright protection in the United States. Approved for public release; distribution is unlimited. 
complicated dynamic impact, this approach to validation can be overly simple and runs the risk of providing a false sense of agreement between measurement and FEA results when such agreement may not exist. Specifically, comparing only the peak values does not take into account whether the time or indentation at which the peak values occur also agree with one another. Indeed, a model and a test may exhibit grossly different responses between initial contact and peak value, except that both reach a similar value for that peak. In this situation, the model may not be capturing the relevant behaviors, but examination of only the peak values may falsely lead to the conclusion that the model is performing as expected.

\section{Overall Curve Shapes}

One of the existing comparisons made between test measurements and FE results is the overall shape of either the force-time or force-indentation response. The overall shape of a dynamic impact response curve is also a recommended comparison in several of the identified design documents. However, this comparison can be a highly-subjective comparison of the agreement or disagreement between two curve shapes. CORA, ISO/TS 18571, and RSVVP have been identified as potential approaches for creating a quantitative comparison between curve shapes.

\section{Energy Metrics}

At the instant of impact, the kinetic energy of the initiallymoving ram can be readily calculated using the velocity of the impactor and its mass. The energy imparted to the tank can be determined by first calculating the force-indentation response from the acceleration- and indentation-time histories for the ram car, and then numerically integrating the force-displacement response. As described in EN 15227, the energy absorbed during a dynamic impact is often a relevant result to be compared between test and analysis. For the tank car shell impact problem, the energy absorbed by the tank will either be equal to the initial kinetic energy (in the event of a non-puncture outcome), or will be less than the initial kinetic energy (if the tank punctures). Regardless of the puncture/non-puncture outcome of the test, the energy that the model predicts the tank should be able to absorb should be compared with the energy absorbed by the tank within the test.

\section{Fluid Response}

As demonstrated by the test results presented earlier in this paper, the fluid behavior inside the tank car can have a significant effect on the overall impact response of the tank car. The DOT-105 and DOT-117 tests exhibited differently-shaped force-time histories owing at least partially to the DOT-105 tank car being initially pressurized and having a larger outage than the DOT-117 tank car.

One of the challenges associated with using test data to validate a model that will then be extrapolated to impact conditions beyond those tested is how valid the model remains as the conditions differ more significantly from what was tested. Because of the differences observed in pressurized and nonpressurized tank car responses, modeling techniques that are appropriate to model one state of pressure may not be equally suitable to model the other state of pressure. Significant changes to the impact setup, such as impactors of a different shape or size, may also have an effect on the relative significance of the fluid behavior. A validation framework may need to take into account the nature of the test and analysis initially used to validate the tank car shell impact model, and determine appropriate limits on the nature of the changes for which that model remains valid.

\section{Puncture/Non-puncture Outcome}

During the impact test itself, one of the readily apparent outcomes is whether the tank has punctured, or if the tank resisted the impact without puncturing. If an FE model is used to simulate a test with the potential of a puncture outcome, the model must also be capable of simulating puncture. The quality of the puncture simulation will depend on such details as the availability of material coupons for testing, the ability of the failure/fracture behavior of the material to be characterized based upon those material tests, and the ability of the FE software to numerically implement the failure/fracture behavior.

Further, it may be appropriate to consider puncture not as a binary outcome, but to take into account the character of the puncture in assessing the performance of the model. For example, if a model predicts puncture for a test situation in which puncture occurred, do both the test and the model experience puncture in the same physical area? Do both the test and model experience puncture at the same time in the impact, or after the same amount of tank indentation? Do both the test and model experience puncture after the same amount of energy has been imparted to the struck tank?

\section{CONCLUDING REMARKS}

FRA has sponsored a series of tests and corresponding FE analyses of shell impact tests of fluid-filled railroad tanks cars. While the test measurements have been compared with the results of corresponding FE models, specific model validation procedures have not yet been adopted for validating tank car shell impact models. As a starting point at choosing both the behaviors to be compared and the threshold for determining suitable agreement for validation, existing model validation criteria and procedures used by other segments of the transportation industry have been reviewed. Several promising approaches to validation that appear to be well-suited to the compliexities of the tank car shell impact problem have been identified. Future work is planned to develop a model validation plan that combines desirable elements from existing approaches to model validation. Additional criteria and procedures specific to the tank car shell impact problem may also be considered for inclusion in a model validation program.

\section{ACKNOWLEDGEMENTS}

The testing described in this paper was performed by Transportation Technology Center, Inc., in Pueblo, Colorado. Dr. Przemek Rakoczy and Mr. Travis Gorhum lead the testing effort. The authors wish to acknowledge Dr. Shaun Eshraghi of the Volpe Center for his work developing the TC128 material characteristics used in the FE models. The authors also wish to

This material is declared a work of the U.S. Government and is not subject to copyright protection in the United States. Approved for public release; distribution is unlimited. 
acknowledge the contributions of Dr. David Jeong (retired) of the Volpe Center to the overall success of the tank car structural integrity research program.

\section{REFERENCES}

[1]. Tank-head puncture-resistance systems. 49 CFR $§ 179.16$ 2015. https://www.gpo.gov/fdsys/pkg/CFR-2015-title49vol3/pdf/CFR-2015-title49-vol3-sec179-16.pdf (Accessed March 8, 2018).

[2]. American Society of Mechanical Engineers. Guide for Verification and Validation in Computational Solid Mechanics. ASME V\&V 10-2006. 2006.

[3]. Carolan, M., and Rakoczy, P. Side Impact Test and Analysis of a DOT-105 Tank Car. U.S. Department of Transportation (in publication).

[4]. Rakoczy, P., Carolan, M., Gorhum, T., and Eshraghi, S. Side Impact Test and Analysis of a DOT-117 Tank Car. U.S. Department of Transportation (in publication).

[5]. Kirkpatrick, S.W., Rakoczy, P., MacNeill, R.A. Side Impact Test and Analyses of a DOT 111 Tank Car. U.S. Department of Transportation, DOT/FRA/ORD/15-30, October, 2015. http://www.fra.dot.gov/eLib/Details/L17092 (Accessed January 13, 2017).

[6]. Rakoczy, P., and Carolan, M. Side Impact Test and Analysis of a DOT-112 Tank Car. U.S. Department of Transportation, DOT/FRA/ORD-16/38, December, 2016. http://www.fra.dot.gov/eLib/Details/L18451 (Accessed January 13, 2017).

[7]. Carolan, M., Jeong, D., Perlman, B., Murty, Y., Namboodri, S., Kurtz, B., Elzey, R., Anankitpaiboon, S., Tunna, L., and Fries, R. Application of Welded Steel Sandwich Panels for Tank Car Shell Impact Protection. U.S. Department of Transportation, DOT/FRA/ORD-13/19, April,2013. https://www.fra.dot.gov/eLib/details/L04507\#p1_z5_gD_k sandwich (Accessed March 8, 2018).

[8]. SAE International. Instrumentation for Impact Test, Part 1, Electronic Instrumentation. SAE J211-1 (1995).

[9]. Abaqus version 6.14. Dassault Systems Simulia Corp, Providence, RI, 2014.

[10]. Bao, Y., Wierzbicki, T., 2004: On fracture locus in the equivalent strain and stress triaxiality space, International Journal of Mechanical Sciences 46, 81-98.

[11]. Y.W. Lee and T. Wierzbicki, Quick Fracture Calibration for Industrial Use, Impact \& Crashworthiness Laboratory Report No. 115, August 2004.

[12]. ASTM E8 / E8M-16a, Standard Test Methods for Tension Testing of Metallic Materials, ASTM International, West Conshohocken, PA, 2016, www.astm.org.

[13]. EN 15227, Railway Applications-Crashworthiness Requirements for Railway Vehicle Bodies, Ref. No. EN 15227:2008:E. 2008.a
[14]. Carolan, M., Jacobsen, K., Llana, P., Severson, K., Perlman, B., and Tyrell, D. Technical Criteria and Procedures for Evaluating the Crashworthiness and Occupant Protection Performance of Alternatively Designed Passenger Rail Equipment for Use in Tier I Service. U.S. Department of Transportation. DOT/FRA/ORD-11/22. 2011. https://www.fra.dot.gov/eLib/Details/L01292 (Accessed February 3, 2018)

[15]. Notice of Proposed Rulemaking. Passenger Equipment Safety Standards; Standards for Alternative Compliance and High-Speed Trainsets. U.S. Department of Transportation, Federal Railroad Administration. 81 FR 88006. December 6, 2016.

https://www.federalregister.gov/documents/2016/12/06/201 6-28280/passenger-equipment-safety-standards-standardsfor-alternative-compliance-and-high-speed-trainsets (Accessed March 8, 2018).

[16]. American Association of State Highway and Transportation Officials (AASHTO). Manual for Assessing Safety Hardware, Second Edition. 2016.

[17]. National Academies of Sciences, Engineering, and Medicine. 2011. Procedures for Verification and Validation of Computer Simulations Used for Roadside Safety Applications. Washington, DC: The National Academies Press. https://doi.org/10.17226/17647 (Accessed March 8, 2018).

[18]. Mongiardini, M., and Ray, M.H. Roadside Safety Verification and Validation Program (RSVVP) Users' Manual. Revision 1.4, December 2009. http://roadsafellc.com/NCHRP22-24/QPR/AttachmentD7.pdf (Accessed March 8, 2018).

[19]. CORrelation and Analysis (CORA) Software, Version 3.6.1. pdb - Partnership for Dummy Technology and Biomechanics. http://www.pdb-org.com/en/information/18cora-download.html (Accessed March 8, 2018).

[20]. International Organization for Standardization. (2014). Road vehicles -- Objective rating metric for non-ambiguous signals. (ISO/TS Standard No. 18571:2014).

[21]. U.S. Department of Transportation, Federal Aviation Administration. Methodology for Dynamic Seat Certification by Analysis for Use in Parts 23, 25, 27, and 29 Airplanes and Rotorcraft. AC 20-146. May 19, 2003. https://www.faa.gov/regulations_policies/advisory_circular s/index.cfm/go/document.information/documentID/22205 (Accessed March 8, 2018).

This material is declared a work of the U.S. Government and is not subject to copyright protection in the United States. Approved for public release; distribution is unlimited. 